\title{
Análisis de la planeación estratégica de la comunicación en cuatro proyectos de intervención social en Montería*
}

\author{
Ana Lorena Malluk Marenco** \\ Recibido: 15 noviembre de 2012 - Aprobado: 23 de enero de 2013
}

\section{Resumen}

El artículo plantea los desafíos que enfrentan los profesionales, las organizaciones gestoras de iniciativas sociales y los beneficiarios, en torno al proceso de planeación de la comunicación de los proyectos de intervención social llevados a cabo en la ciudad de Montería.

Se analizaron cuatro programas de comunicación estratégica de los proyectos Reciclando Ando, Plan Departamental de Aguas, Implementación de Parcelas Productivas y Desarrollo Sostenible de las Artesanías de Córdoba, desarrollados por las organizaciones Servigenerales/UPB, Gobernación Córdoba, Fundación Santa Isabel y la Corporación de los Valles del Sinú y San Jorge, respectivamente. Se realizó un análisis individual de cada caso, que incluyó diferentes estrategias de contacto con la realidad objeto de estudio, como el análisis documental, la entrevista, el grupo focal y la observación participante, lo que permitió metodológicamente alimentar la documentación teórica, la interpretación de evidencias y la interacción del investigador con los actores y sus realidades.

Los resultados evidenciaron que estas instituciones relegan la comunicación a un uso instrumental; no la emplean de forma estratégica (sistemática, organizada, probada, integradora y articulada al proceso de planeación de los proyectos de intervención social) y no incluyen mecanismos de integración y participación activa de los grupos de interés involucrados con estas iniciativas.

Palabras clave: Cambio social, comunicación estratégica, intervención social.

* Este artículo es resultado del Proyecto de Grado "Análisis del proceso de la planeación del programa de comunicación estratégica de los proyectos de intervención social llevados a cabo por las organizaciones gubernamentales, mixtas y no gubernamentales de la ciudad de Montería, durante el período 2006-2009", para optar el título de Magíster en Comunicación que otorga la Fundación Universidad del Norte. La presente investigación se desarrolló en el marco del convenio interinstitucional entre las Universidades del Norte y Pontificia Bolivariana de Montería.

** Comunicadora social-periodista de la Universidad Pontificia Bolivariana, magíster en Comunicación de la Universidad del Norte, especialista en Gerencia de la Universidad Pontificia Bolivariana. Consultora empre-

Anagramas Volumen 11, № 22 pp. 79-92 ISSN 1692-2522 Enero-Junio de 2013. 212 p. Medellín, Colombia 


\title{
Analysis of Communication Strategic Planning in four Social Intervention Projects in Montería
}

\begin{abstract}
This article refers to the challenge faced by professionals, organizations interested in social initiatives and beneficiaries around social intervention projects communication planning process carried out in Monteria city.

Four programs of project strategic communication were analyzed: "We are Recycling, State Water Plans, Implementation of Productive Areas, and sustainable Development of Cordoba handcrafts, developed by the following organizations: Servigenerales/UPB, Gobernación Córdoba, Fundación Santa Isabel, and Corporación de los Valles del Sinú and San Jorge, respectively. An individual analysis of each case was carried out. It included different contact strategies with the study object such as documental analysis, the interview, focal group, and participant observation which allowed feeding -methodologically - theoretical documentation, interpretation of evidences, and the interaction of the researcher with agents and their realities.

Results showed that these institutions give communication am instrumental use, they do not use it in a strategic way (systematic, organized, proved, integrating, and articulated to the planning process of social intervention projects) and doe not include integration and active participation mechanisms of interest groups involved in these initiatives.
\end{abstract}

Key words: Social change, Social change, strategic communication, social intervention.

sarial en el área de Gestión de la Comunicación. Investigadora del grupo COEDU Comunicación y Educación. Directora del Semillero de Investigación GECO Gestores Comunitarios. Gestora y Coordinadora de los Programas de Proyección Social Reciclando Ando y Amigos del Parque. Actualmente es docente interna de la Facultad de Comunicación Social- Periodismo de la Universidad Pontificia Bolivariana, Montería. Autora de libro "Reciclando ando: la nueva cultura del reciclaje" EAE, 2011. Email: ana.malluk@upbmonteria. edu.co,ana_malluk@hotmail.com. 


\section{Introducción}

En ciudades como Montería, la planeación de la comunicación demanda atención, no solo por parte de las organizaciones que llevan a cabo procesos de intervención, sino también del Gobierno, la empresa privada, los organizaciones no gubernamentales, las agencias de cooperación, la comunidad, las facultades de Comunicación Social y demás actores que de una u otra forma se encuentran involucrados y que realizan esfuerzos que no siempre obedecen a procesos sistemáticos y planeados.

Los actores vinculados en la intervención social deben definir un marco conceptual y práctico que les permita articular la comunicación para el cambio social a los procesos de planeación de estos proyectos, con el fin de dinamizar el rol horizontal, de doble vía, y participativo de la comunicación; proponer acciones que correspondan a sus necesidades y expectativas; reconocer la participación, el consenso y la acción colectiva como insumos para potenciar sus capacidades; promover cambios de pensamiento, conocimiento, actitudes, habilidades y/o comportamientos; o como lo plantea Beltrán (1995) "cohesionar el trabajo de quienes formulan las políticas orientadas al desarrollo y las comunidades vulnerables a quienes van dirigidas estas políticas".

La presente investigación no solo evidenció el estado actual del proceso de planeación del programa de comunicación estratégico que realizan las organizaciones gubernamentales, mixtas y no gubernamentales en sus proyectos de intervención social, sino que también amplió el horizonte en cuanto al uso de la comunicación estratégica en procesos de cambio social, más aún, en Montería donde las evidencias recopiladas demuestran cómo los gestores de los proyectos, tal como lo afirma Gumucio (2001), relegan o ignoran la comunicación, invirtiendo sus esfuerzos y recursos en la difusión de información, en estrategias que fomenten la visibilidad institucional o en todo aquello que facilite la gestión organizacional, y que, además, promueva el reconocimiento del proyecto y de la entidad, a través de la publicidad.

De manera complementaria, abona el camino para proyectos de investigación que busquen analizar el rol de la comunicación en los procesos de movilización y se constituye en fuente de conocimiento y directriz para comprender el proceso de la planeación de la comunicación estratégica teniendo en cuenta la concepción del proceso, el modelo de planeación empleado, el diseño del proceso, la coherencia metodológica del programa, las fases llevadas a cabo y sus respectivas características, el nivel de participación de los involucrados y las percepciones de los beneficiados con respecto a los resultados, impacto y cambios sociales.

Finamente este estudio propuso un análisis de la coherencia del diseño del programa de comunicación estratégica, lo que implicó "examinar el programa respecto a un conjunto de criterios que se aplican de manera relativa o absoluta" (McMillan, James, 2005, p. 560).

En Colombia y en Montería, son pocos los estudios que abordan el tema de esta investigación; así el hecho de caracterizar este proceso de planeación de la comunicación se considera un paso importante en el ámbito de la investigación y un aporte valioso. 


\section{Metodología}

La investigación incluyó diferentes estrategias de contacto con la realidad objeto de estudio como el diálogo propio de la entrevista, la reflexión y la construcción colectiva - característica de los talleres con grupos focales- y la vivencia alcanzada a través de la observación participante.

En el presente caso se emplearon las siguientes técnicas:

- Análisis de los documentos institucionales proporcionados por las organizaciones (diagnósticos, informes, actas, registros fotográficos, etc.) con información del proyecto y/o programa de comunicación.

- Dos sesiones de entrevistas estructuradas realizadas a los coordinadores, comunicadores sociales, profesionales encargados del componente social o responsables de diseñar, implementar y evaluar el programa de comunicación.

- Una sesión de entrevista a grupo focal, dirigida a las personas beneficiadas de los programas (líderes, madres comunitarias y estudiantes de instituciones educativas).

- La observación no participante se utilizó para el trabajo con los grupos focales y permitió conocer las percepciones y el reconocimiento que las comunidades beneficiadas tuvieron del proceso de planeación y de su impacto y resultados.

El universo estuvo conformado por los programas de comunicación estratégica llevados a cabo durante el período 2006-2009 por organizaciones gubernamentales, mixtas y no gubernamentales. La muestra la constituyeron cuatro programas de comunicación estratégica llevados a cabo por instituciones de la empresa privada, entidad pública, economía mixta y ONG. Con respecto al diseño, la estrategia metodológica de investigación que se empleó fue el estudio múltiple de caso.

Tabla 1. Programas y organizaciones objeto de estudio

\begin{tabular}{|l|l|l|}
\hline Programa & Organización & Año \\
\hline $\begin{array}{l}\text { Reciclando Ando en el sector Las Cañas del barrio Canta Claro } \\
\text { de Montería }\end{array}$ & Servigenerales & 2008 \\
\hline Plan Departamental de Aguas en Venados Campanito & $\begin{array}{l}\text { Gobernación Córdo ba a } \\
\text { (Aguas de Córdoba) }\end{array}$ & 2009 \\
\hline $\begin{array}{l}\text { Implementación de Parcelas Productivas, como estrategia de } \\
\text { mejoramiento de la Seguridad Alimentaria -ReSA (El Cerrito } \\
\text { de Montería) }\end{array}$ & Fundación Santa Isabel & 2009 \\
\hline $\begin{array}{l}\text { Desarrollo Sostenible de las Artesanías de Córdoba elaborar } \\
\text { das en enea, cañaflecha, calceta de plátano y lata de corozo, } \\
\text { para la generación de productos para el Mercado Verde en Mi } \\
\text { Ranchito de Montería }\end{array}$ & $\begin{array}{l}\text { La Corporación de los Valles } \\
\text { del Sinú y San Jorge (Unidad } \\
\text { de Producción Más Limpia) }\end{array}$ & \\
\hline
\end{tabular}

Fuente: Ana Lorena Malluk Marenco 
De igual forma, se escogieron cuatro modelos de planeación del programa de comunicación estratégica planteados por organizaciones como la Alianza para la Comunicación en Salud, la FAO, la USAID y el Ministerio de Salud del Perú, como marco de referencia para determinar la coherencia del diseño y gestión del programa de comunicación estratégica.

Tabla 2. Modelos seleccionados

\begin{tabular}{|c|l|l|l|}
\hline \multicolumn{2}{|c|}{ Modelos Verticales } & \multicolumn{2}{c|}{ Modelos Horizontales } \\
\hline \multicolumn{1}{|c|}{ Nombre } & \multicolumn{1}{|c|}{ Organización } & \multicolumn{1}{c|}{ Nombre } & Organización \\
\hline $\begin{array}{l}\text { El Nuevo Proceso } \\
\text { P }\end{array}$ & $\begin{array}{l}\text { Alianza para la Comu- } \\
\text { nicación en Salud -HCP }\end{array}$ & $\begin{array}{l}\text { Diagnóstico participativo y Di- } \\
\text { seño participativo para una } \\
\text { estrategia de comunicación }\end{array}$ & SADC y FAO \\
\hline $\begin{array}{l}\text { Comunicación y } \\
\text { educación para la } \\
\text { promoción de la } \\
\text { salud }\end{array}$ & $\begin{array}{l}\text { Ministerio de Salud del } \\
\text { Perú }\end{array}$ & $\begin{array}{l}\text { Guía para la implementación de } \\
\text { estrategias de comunicación en } \\
\text { municipalidades }\end{array}$ & USAID \\
\hline
\end{tabular}

Fuente: Ana Lorena Malluk Marenco

El tipo de muestreo que se utilizó fue intencional. El conjunto de criterios de inclusión referidos a los sujetos de estudio y a sus características específicas fueron:

- Experiencia representativa de las organizaciones.

- Proyectos de intervención social reconocidos por sus resultados e impacto.

- Reconocimiento de la comunicación como dinamizadora de los proyectos de intervención social.

- Interés por analizar el proceso de planeación del programa de comunicación.

- Disponibilidad de las organizaciones para hacer parte de la investigación.

- Información de calidad del proceso de planeación de este programa.

- Acceso a las comunidades beneficiadas.

La aplicación de los instrumentos anteriormente abordados se realizó a partir de las siguientes categorías de análisis previas: usos y enfoques de la comunicación, intervención social, modelos de planeación de programas de comunicación y programa de comunicación estratégico.

\section{Resultados}

Los resultados que se presentan a continuación son producto de la interrelación sistemática de los instrumentos y las categorías adelantadas en el trabajo de campo. 
Tabla 3. Categorías y subcategorías de análisis preestablecidas

\begin{tabular}{|l|l|}
\hline Categorias & Subcategorías \\
\hline $\begin{array}{l}\text { Usos y enfoques de } \\
\text { la comunicación }\end{array}$ & $\begin{array}{l}* \text { Comunicación instrumental o vertical } \\
* \text { Comunicación horizontal o participativa } \\
* \text { Importancia e influencia de la comunicación en el cambio }\end{array}$ \\
\hline Intervención social & $\begin{array}{l}* \text { Dirigida } \\
\text { * Participativa }\end{array}$ \\
\hline $\begin{array}{l}\text { Modelos de planea- } \\
\text { ción de programas } \\
\text { de comunicación }\end{array}$ & $\begin{array}{l}* \text { Fercepción de la comunidad beneficiada } \\
\text { * Tipo de modelo }\end{array}$ \\
\hline $\begin{array}{l}\text { Programa de comu- } \\
\text { nicación estratégica }\end{array}$ & $\begin{array}{l}* \text { Proceso estructurado de acciones comunicativas } \\
* \text { Fases o etapas de los programas }\end{array}$ \\
\hline
\end{tabular}

Categoría 1: Usos y enfoques de la comunicación

\begin{tabular}{|c|c|c|c|c|}
\hline Sub categoría & $\begin{array}{l}\text { Caso } 1 \\
\text { Reciclando ando }\end{array}$ & $\begin{array}{c}\text { Caso } 2 \\
\text { Plan departamental de } \\
\text { aguas - pda }\end{array}$ & $\begin{array}{c}\text { Caso } 3 \\
\text { Seguridad alimentaria } \\
\text {-resa }\end{array}$ & $\begin{array}{l}\text { Caso } 4 \text { desarrollo soste- } \\
\text { nible de las artesanías }\end{array}$ \\
\hline \multirow[t]{2}{*}{$\begin{array}{l}\text { Comunica- } \\
\text { ción vertical } \\
\text { /Comunica- } \\
\text { ción hori- } \\
\text { zontal }\end{array}$} & $\begin{array}{l}\text { La comunicación fue } \\
\text { usada como medio; sir- } \\
\text { vió como herramienta } \\
\text { para enviar mensajes } \\
\text { claros y sencillos al pú- } \\
\text { blico interno y externo. }\end{array}$ & $\begin{array}{l}\text { La comunicación } \\
\text { fue empleada como } \\
\text { medio para divulgar } \\
\text { información y dar a } \\
\text { conocer al público lo } \\
\text { que se está haciendo } \\
\text { bajos ciertos pará- } \\
\text { metros. }\end{array}$ & $\begin{array}{l}\text { La comunicación se } \\
\text { usó como medio; faci- } \\
\text { litó el contacto directo } \\
\text { y la información cons- } \\
\text { tante entre los gesto- } \\
\text { res y la comunidad. }\end{array}$ & $\begin{array}{l}\text { La comunicación se } \\
\text { empleó como medio } \\
\text { para establecer con- } \\
\text { tacto directo entre las } \\
\text { comunidades y la CVS }\end{array}$ \\
\hline & $\begin{array}{l}\text { El enfoque de la comu- } \\
\text { nicación fue vertical; la } \\
\text { comunicación se em- } \\
\text { peló para informar del } \\
\text { proyecto, de las deci- } \\
\text { siones tomadas por los } \\
\text { gestores y se motivó a la } \\
\text { comunidad a participar } \\
\text { de la fase de implemen- } \\
\text { tación. }\end{array}$ & $\begin{array}{l}\text { El enfoque de la co- } \\
\text { municación fue verti- } \\
\text { cal; la comunicación } \\
\text { sirvió para responder } \\
\text { inquietudes, mostrar } \\
\text { avances de las obras } \\
\text { a través de los me- } \\
\text { dios, informar a los } \\
\text { órganos de control de } \\
\text { la gestión del proyecto } \\
\text { y rendir cuentas de los } \\
\text { recursos invertidos. }\end{array}$ & $\begin{array}{l}\text { El enfoque de la co- } \\
\text { municación fue verti- } \\
\text { cal, la comunicación } \\
\text { sirvió para informar a } \\
\text { los beneficiarios sobre } \\
\text { el proyecto, para pre- } \\
\text { sentar resultados a la } \\
\text { agencia financiadora } \\
\text { y para motivar a la co- } \\
\text { munidad a vincularse } \\
\text { al programa. }\end{array}$ & $\begin{array}{l}\text { El enfoque de la co- } \\
\text { municación fue verti- } \\
\text { cal, esta fortaleció la } \\
\text { relación con los bene- } \\
\text { ficiarios, el Gobierno } \\
\text { y los medios, y ayudó } \\
\text { al reconocimiento del } \\
\text { proyecto y de la labor } \\
\text { social y ambiental que } \\
\text { cumple la organiza- } \\
\text { ción. }\end{array}$ \\
\hline
\end{tabular}


Análisis de la planeación estratégica de la comunicación en cuatro proyectos de intervención social en Montería

\begin{tabular}{|c|c|c|c|c|}
\hline Sub categoría & $\begin{array}{c}\text { Caso } 1 \\
\text { Reciclando ando }\end{array}$ & $\begin{array}{c}\text { Caso } 2 \\
\text { Plan departamental de } \\
\text { aguas - pda }\end{array}$ & $\begin{array}{c}\text { Caso } 3 \\
\text { Seguridad alimentaria } \\
\text { resa }\end{array}$ & $\begin{array}{l}\text { Caso } 4 \text { desarrollo soste- } \\
\text { nible de las artesanías }\end{array}$ \\
\hline $\begin{array}{l}\text { Importancia } \\
\text { e influencia } \\
\text { de la comu- } \\
\text { nicación en } \\
\text { el cambio }\end{array}$ & $\begin{array}{l}\text { La comunicación fue } \\
\text { medio o herramienta } \\
\text { para lograr los objetivos } \\
\text { del proyecto; aunque su } \\
\text { uso promovió cambios } \\
\text { de comportamientos en } \\
\text { cuanto a la separación } \\
\text { en la fuente, esta no fue } \\
\text { entendida y concebida } \\
\text { como motor fundamen- } \\
\text { tal de los procesos de } \\
\text { cambio que asumiría el } \\
\text { grupo social. }\end{array}$ & $\begin{array}{l}\text { La comunicación fue } \\
\text { herramienta para lo- } \\
\text { grar los objetivos del } \\
\text { proyecto; aunque su } \\
\text { uso promovió cambios } \\
\text { de comportamientos } \\
\text { en cuanto a las buenas } \\
\text { prácticas en el uso } \\
\text { del servicio del agua y } \\
\text { saneamiento básico, } \\
\text { esta no fue entendida } \\
\text { y concebida como mo- } \\
\text { tor fundamental de los } \\
\text { procesos de cambio } \\
\text { que asumiría el grupo } \\
\text { social. }\end{array}$ & $\begin{array}{l}\text { La comunicación fue } \\
\text { medio para alcanzar } \\
\text { los objetivos del pro- } \\
\text { yecto y para difundir } \\
\text { sus resultados a Ac- } \\
\text { ción Social; aunque } \\
\text { su uso promovió } \\
\text { cambios de compor- } \\
\text { tamientos en cuanto a } \\
\text { la implementación de } \\
\text { parcelas productivas, } \\
\text { esta no fue concebida } \\
\text { como motor indispen- } \\
\text { sable de los procesos } \\
\text { de cambio del grupo } \\
\text { social. }\end{array}$ & $\begin{array}{l}\text { La comunicación fue } \\
\text { "una cosa importante" } \\
\text { para lograr las me- } \\
\text { tas propuestas en el } \\
\text { plan de gestión de la } \\
\text { CVS; aunque su uso } \\
\text { promovió cambios } \\
\text { de pensamiento en } \\
\text { cuanto a la fabrica- } \\
\text { ción de artesanías y su } \\
\text { comercialización, no } \\
\text { fue entendida como } \\
\text { eje primordial de los } \\
\text { procesos de cambio } \\
\text { que asumiría el grupo } \\
\text { social. }\end{array}$ \\
\hline
\end{tabular}

Fuente: Ana Lorena Malluk Marenco

Categoría 2: Intervención social

\begin{tabular}{|c|c|c|c|c|}
\hline $\begin{array}{l}\text { Sub cate- } \\
\text { goría }\end{array}$ & $\begin{array}{l}\text { Caso } 1 \\
\text { Reciclando ando }\end{array}$ & $\begin{array}{c}\text { Caso } 2 \\
\text { Plan departamental de } \\
\text { aguas - pda }\end{array}$ & $\begin{array}{c}\text { Caso } 3 \\
\text { Seguridad alimentaria } \\
\text {-resa }\end{array}$ & $\begin{array}{l}\text { Caso } 4 \text { desarrollo soste- } \\
\text { nible de las artesanías }\end{array}$ \\
\hline $\begin{array}{l}\text { Dirigida / } \\
\text { participa- } \\
\text { tiva }\end{array}$ & $\begin{array}{l}\text { El tipo de interven- } \\
\text { ción fue dirigida; el } \\
\text { grupo gestor fue el } \\
\text { encargado de pla- } \\
\text { near todo lo refe- } \\
\text { rente al proyecto y } \\
\text { la comunidad solo } \\
\text { participó activa- } \\
\text { mente en la fase de } \\
\text { implementación. }\end{array}$ & $\begin{array}{l}\text { El tipo de interven- } \\
\text { ción fue dirigida; los } \\
\text { gestores fueron los } \\
\text { encargados de pla- } \\
\text { near el programa y la } \\
\text { comunidad solo par- } \\
\text { ticipó activamente } \\
\text { en la conformación } \\
\text { y sostenibilidad de la } \\
\text { asociación de usua- } \\
\text { rios, encargada de } \\
\text { la sostenibilidad del } \\
\text { proyecto. }\end{array}$ & $\begin{array}{l}\text { El tipo de interven- } \\
\text { ción fue dirigida; los } \\
\text { gestores fueron los } \\
\text { encargados de pla- } \\
\text { near el programa y } \\
\text { la comunidad solo } \\
\text { participó activamen- } \\
\text { te en la selección de } \\
\text { los insumos que se } \\
\text { emplearon, en el } \\
\text { tipo de productos } \\
\text { que se sembraron y } \\
\text { en el cultivo de las } \\
\text { parcelas. }\end{array}$ & $\begin{array}{l}\text { El tipo de interven- } \\
\text { ción fue dirigida; los } \\
\text { gestores fueron los } \\
\text { encargados de pla- } \\
\text { near el programa y } \\
\text { la comunidad solo } \\
\text { participó activamen- } \\
\text { te en el desarrollo de } \\
\text { los nuevos modelos } \\
\text { de fabricación de la } \\
\text { enea. }\end{array}$ \\
\hline $\begin{array}{l}\text { Resultados } \\
\text { e impacto }\end{array}$ & $\begin{array}{l}\text { Los resultados e } \\
\text { impacto estuvieron } \\
\text { asociados al logro de } \\
\text { los objetivos y metas } \\
\text { y no a las percepcio- }\end{array}$ & $\begin{array}{l}\text { Los resultados e im- } \\
\text { pacto del programa } \\
\text { fueron confundidos } \\
\text { con los del proyecto. } \\
\text { No existen eviden- }\end{array}$ & $\begin{array}{l}\text { Los resultados e } \\
\text { impacto estuvieron } \\
\text { asociados al cumpli- } \\
\text { miento de los indica- } \\
\text { dores establecidos }\end{array}$ & $\begin{array}{l}\text { Se desconoce si el } \\
\text { área de prensa rea- } \\
\text { lizó un estudio para } \\
\text { conocer los resulta- } \\
\text { dos e impacto; aun- }\end{array}$ \\
\hline
\end{tabular}




\begin{tabular}{|c|c|c|c|c|}
\hline $\begin{array}{l}\text { Sub cate- } \\
\text { goría }\end{array}$ & $\begin{array}{l}\text { Caso } 1 \\
\text { Reciclando ando }\end{array}$ & $\begin{array}{c}\text { Caso } 2 \\
\text { Plan departamental de } \\
\text { aguas - pda }\end{array}$ & $\begin{array}{c}\text { Caso } 3 \\
\text { Seguridad alimentaria } \\
\text {-resa }\end{array}$ & $\begin{array}{c}\text { Caso } 4 \text { desarrollo soste- } \\
\text { nible de las artesanías }\end{array}$ \\
\hline $\begin{array}{l}\text { Resultados } \\
\text { e impacto }\end{array}$ & $\begin{array}{l}\text { nes de la comuni- } \\
\text { dad con respecto al } \\
\text { proceso de cambio } \\
\text { experimentado, al } \\
\text { logro de los objetivos } \\
\text { de comunicación y } \\
\text { al desarrollo de las } \\
\text { fases del programa } \\
\text { de comunicación. }\end{array}$ & $\begin{array}{l}\text { cias que den cuenta } \\
\text { de un estudio que } \\
\text { evalúe las percepcio- } \\
\text { nes de la comunidad } \\
\text { con respecto al pro- } \\
\text { ceso de cambio, al } \\
\text { logro de los objetivos } \\
\text { y al desarrollo de las } \\
\text { fases del programa } \\
\text { de comunicación. }\end{array}$ & $\begin{array}{l}\text { por Acción Social y } \\
\text { no a las percepcio- } \\
\text { nes de la comunidad } \\
\text { con respecto al pro- } \\
\text { ceso de cambio, al } \\
\text { logro de los objetivos } \\
\text { de comunicación y } \\
\text { al desarrollo de las } \\
\text { fases del programa } \\
\text { de comunicación. }\end{array}$ & $\begin{array}{l}\text { que se puede inferir } \\
\text { que estos estuvieron } \\
\text { asociados al cumpli- } \\
\text { miento de las metas } \\
\text { de la Unidad y no a } \\
\text { las percepciones de } \\
\text { la comunidad. }\end{array}$ \\
\hline $\begin{array}{l}\text { Percepción } \\
\text { de la co- } \\
\text { munidad }\end{array}$ & $\begin{array}{l}\text { Ninguna de las fases } \\
\text { del programa con- } \\
\text { templó la importan- } \\
\text { cia de conocer y re- } \\
\text { gistrar formalmente } \\
\text { la percepción de la } \\
\text { comunidad; sin em- } \\
\text { bargo, el grupo tiene } \\
\text { recordación de las } \\
\text { actividades y gratitud } \\
\text { hacia los gestores del } \\
\text { programa. }\end{array}$ & $\begin{array}{l}\text { En las fases del } \\
\text { programa de comu- } \\
\text { nicación y/o com- } \\
\text { ponente social no } \\
\text { existe el registro de } \\
\text { las percepciones de } \\
\text { la comunidad con } \\
\text { respecto a los re- } \\
\text { sultados e impacto; } \\
\text { la comunidad le dio } \\
\text { más importancia a la } \\
\text { obra que al uso de la } \\
\text { comunicación. }\end{array}$ & $\begin{array}{l}\text { En ninguna de las } \\
\text { fases del programa } \\
\text { de comunicación se } \\
\text { contempló el registro } \\
\text { formal de la percep- } \\
\text { ción de la comuni- } \\
\text { dad. El grupo no tuvo } \\
\text { mucha recordación } \\
\text { de las actividades, } \\
\text { pero si gratitud con } \\
\text { la FSI por los nuevos } \\
\text { saberes adquiridos. }\end{array}$ & $\begin{array}{l}\text { Ninguna de las fases } \\
\text { del programa de co- } \\
\text { municación contem- } \\
\text { pló la importancia } \\
\text { de conocer y regis- } \\
\text { trar formalmente } \\
\text { la percepción de la } \\
\text { comunidad. El grupo } \\
\text { rechazó el tratamien- } \\
\text { to que la dio la CVS al } \\
\text { proyecto. }\end{array}$ \\
\hline
\end{tabular}

Fuente: Ana Lorena Malluk Marenco

Resultados individuales Categoría 3: Modelos de planeación de programas de comunicación

\begin{tabular}{|c|c|c|c|c|}
\hline $\begin{array}{c}\text { Sub } \\
\text { categoría }\end{array}$ & $\begin{array}{l}\text { Caso } 1 \\
\text { Reciclando ando }\end{array}$ & $\begin{array}{c}\text { Caso } 2 \\
\text { Plan departamental de } \\
\text { aguas - pda }\end{array}$ & $\begin{array}{c}\text { Caso } 3 \\
\text { Seguridad alimentaria } \\
\text {-resa }\end{array}$ & $\begin{array}{l}\text { Caso } 4 \text { desarrollo } \\
\text { sostenible de las } \\
\text { artesanías }\end{array}$ \\
\hline $\begin{array}{l}\text { Fortalezas } \\
\text { y debili- } \\
\text { dades en } \\
\text { la planea- } \\
\text { ción de } \\
\text { programas } \\
\text { de comu- } \\
\text { nicación }\end{array}$ & $\begin{array}{l}\text { Las fortalezas fueron } \\
\text { la unión de esfuerzos } \\
\text { de las organizacio- } \\
\text { nes gestoras, el co- } \\
\text { nocimiento del tema } \\
\text { por parte de la UPB } \\
\text { y la experiencia en el } \\
\text { trabajo comunitario } \\
\text { de Servigenerales. }\end{array}$ & $\begin{array}{l}\text { Las fortalezas fueron } \\
\text { el trabajo en equipo, } \\
\text { la transparencia en la } \\
\text { gestión de los recur- } \\
\text { sos, la participación } \\
\text { de la comunidad por } \\
\text { ley y la organización } \\
\text { del grupo social para } \\
\text { el mantenimiento y } \\
\text { sostenibilidad del }\end{array}$ & $\begin{array}{l}\text { Las fortalezas fue- } \\
\text { ron la posibilidad de } \\
\text { divulgar información } \\
\text { del proyecto por los } \\
\text { medios masivos, la } \\
\text { sensibilización de la } \\
\text { comunidad y el uso } \\
\text { de técnicas de culti- } \\
\text { vo y de alimentación } \\
\text { alternativa. }\end{array}$ & $\begin{array}{l}\text { La principal fortaleza } \\
\text { fue la alianza inte- } \\
\text { rinstitucional entre la } \\
\text { CVS, el SENA, Arte- } \\
\text { sanías de Colombia y } \\
\text { la comunidad. } \\
\text { Las principales debi- } \\
\text { lidades fueron la falta } \\
\text { de acompañamiento } \\
\text { y asesoría de la CVS }\end{array}$ \\
\hline
\end{tabular}


Análisis de la planeación estratégica de la comunicación en cuatro proyectos de intervención social en Montería

\begin{tabular}{|c|c|c|c|c|}
\hline $\begin{array}{l}\text { Sub } \\
\text { categoría }\end{array}$ & $\begin{array}{c}\text { Caso } 1 \\
\text { Reciclando ando }\end{array}$ & $\begin{array}{c}\text { Caso } 2 \\
\text { Plan departamental de } \\
\text { aguas - pda }\end{array}$ & $\begin{array}{c}\text { Caso } 3 \\
\text { Seguridad alimentaria } \\
\text {-resa }\end{array}$ & $\begin{array}{c}\text { Caso } 4 \text { desarrollo } \\
\text { sostenible de las } \\
\text { artesanías }\end{array}$ \\
\hline $\begin{array}{l}\text { Fortalezas } \\
\text { y debili- } \\
\text { dades en } \\
\text { la planea- } \\
\text { ción de } \\
\text { programas } \\
\text { de comu- } \\
\text { nicación }\end{array}$ & $\begin{array}{l}\text { Las debilidades fue- } \\
\text { ron el poco tiempo } \\
\text { de duración del } \\
\text { proyecto; la falta de } \\
\text { acompañamiento } \\
\text { por parte de Servige- } \\
\text { nerales; y los pocos } \\
\text { sectores beneficia- } \\
\text { dos. }\end{array}$ & $\begin{array}{l}\text { servicio del agua. } \\
\text { Aguas de Córdoba no } \\
\text { reconoció debilida- } \\
\text { des; mientras que la } \\
\text { comunidad mencionó } \\
\text { la falta de acompaña- } \\
\text { miento de Acuavalley } \\
\text { de capacitación en lo } \\
\text { referente a la confor- } \\
\text { mación y sostenibili- } \\
\text { dad de la Asociación } \\
\text { de Usuarios. }\end{array}$ & $\begin{array}{l}\text { Las principales debi- } \\
\text { lidades fueron la falta } \\
\text { de capacitación del } \\
\text { grupo gestor en el } \\
\text { manejo de las nue- } \\
\text { vas tecnologías y la } \\
\text { falta de tierras de } \\
\text { la comunidad para } \\
\text { cultivar. }\end{array}$ & $\begin{array}{l}\text { en todo el proceso } \\
\text { de recolección, trata- } \\
\text { miento, producción } \\
\text { y comercialización } \\
\text { de la enea y la falta } \\
\text { de un estudio formal } \\
\text { de las necesidades } \\
\text { del grupo social con } \\
\text { respecto a la proble- } \\
\text { mática. }\end{array}$ \\
\hline $\begin{array}{l}\text { Tipo de } \\
\text { modelo }\end{array}$ & $\begin{array}{l}\text { No se empleó ningún } \\
\text { modelo de planea- } \\
\text { ción del programa } \\
\text { de comunicación, } \\
\text { debido a que no } \\
\text { existen en Servige- } \\
\text { nerales lineamientos } \\
\text { institucionales que } \\
\text { sugieran el uso de un } \\
\text { modelo en particular. }\end{array}$ & $\begin{array}{l}\text { No se empleó ningún } \\
\text { modelo de planea- } \\
\text { ción de la comuni- } \\
\text { cación, ya que no } \\
\text { existe en Aguas de } \\
\text { Córdoba lineamien- } \\
\text { tos que sugieran el } \\
\text { uso de un modelo en } \\
\text { particular. Los reque- } \\
\text { rimientos de la agen- } \\
\text { cia financiadora y los } \\
\text { términos del contrato } \\
\text { sugieren aspectos } \\
\text { que deben ser teni- } \\
\text { dos en cuenta en el } \\
\text { proceso de ejecución } \\
\text { del proyecto, sin que } \\
\text { esto signifique del } \\
\text { uso de un modelo. }\end{array}$ & $\begin{array}{l}\text { Aunque existieron } \\
\text { requerimientos de } \\
\text { la agencia financia- } \\
\text { dora en los que se } \\
\text { fijaron los términos } \\
\text { del contrato para la } \\
\text { ejecución del proyec- } \\
\text { to, esto no significó } \\
\text { el uso de un modelo } \\
\text { de planeación del } \\
\text { programa de comu- } \\
\text { nicación. }\end{array}$ & $\begin{array}{l}\text { Aunque en la CVS } \\
\text { se aplica un modelo } \\
\text { de comunicacional } \\
\text { transversal; se pudo } \\
\text { deducir que este mo- } \\
\text { delo no fue propia- } \\
\text { mente relacionado } \\
\text { con el programa de } \\
\text { comunicación, sino } \\
\text { que hace parte de } \\
\text { una política institu- } \\
\text { cional que implica } \\
\text { que elárea de prensa } \\
\text { debe apoyar a todas } \\
\text { las dependencias y } \\
\text { procesos de la Cor- } \\
\text { poración. }\end{array}$ \\
\hline
\end{tabular}

Fuente: Ana Lorena Malluk Marenco

Resultados individuales Categoría 4: Programa de Comunicación Estratégica

\begin{tabular}{|c|c|c|c|c|}
\hline $\begin{array}{c}\text { Sub } \\
\text { categoría }\end{array}$ & $\begin{array}{c}\text { Caso } 1 \\
\text { Reciclando ando }\end{array}$ & $\begin{array}{c}\text { Caso } 2 \\
\text { Plan departamental de } \\
\text { aguas - pda }\end{array}$ & $\begin{array}{c}\text { Caso } 3 \\
\text { Seguridad alimentaria } \\
\text {-resa } \\
\end{array}$ & $\begin{array}{l}\text { Caso } 4 \text { desarrollo } \\
\text { sostenible de las } \\
\text { artesanías }\end{array}$ \\
\hline $\begin{array}{l}\text { Importancia } \\
\text { e influencia } \\
\text { del progra- } \\
\text { ma de co- } \\
\text { municación } \\
\text { estratégica }\end{array}$ & $\begin{array}{l}\text { Este programa fue } \\
\text { entendido como el } \\
\text { conjunto de metas } \\
\text { y actividades que } \\
\text { permitieron el logro } \\
\text { de los objetivos; }\end{array}$ & $\begin{array}{l}\text { Fue muy escasa la } \\
\text { información propor } \\
\text { cionada en cuanto } \\
\text { a este programa de } \\
\text { comunicación. El } \\
\text { PDA contempló los }\end{array}$ & $\begin{array}{l}\text { El programa fue en- } \\
\text { tendido como la me- } \\
\text { todología fijada por } \\
\text { Acción Social para la } \\
\text { gestión de proyectos. } \\
\text { Contempló el estu- }\end{array}$ & $\begin{array}{l}\text { Este programa per- } \\
\text { mitió estructurar una } \\
\text { serie de actividades, } \\
\text { el tiempo de dura- } \\
\text { ción de estas y los } \\
\text { recursos indispensa- }\end{array}$ \\
\hline
\end{tabular}




\begin{tabular}{|c|c|c|c|c|}
\hline $\begin{array}{c}\text { Sub } \\
\text { categoría }\end{array}$ & $\begin{array}{c}\text { Caso } 1 \\
\text { Reciclando ando }\end{array}$ & $\begin{array}{c}\text { Caso } 2 \\
\text { Plan departamental de } \\
\text { aguas - pda }\end{array}$ & $\begin{array}{c}\text { Caso } 3 \\
\text { Seguridad alimentaria } \\
\text {-resa }\end{array}$ & $\begin{array}{l}\text { Caso } 4 \text { desarrollo } \\
\text { sostenible de las } \\
\text { artesanías }\end{array}$ \\
\hline $\begin{array}{l}\text { I m por- } \\
\text { tancia e } \\
\text { influencia } \\
\text { del pro- } \\
\text { grama de } \\
\text { comunica- } \\
\text { ción estra- } \\
\text { tégica }\end{array}$ & $\begin{array}{l}\text { contempló la alianza } \\
\text { interinstitucional, el } \\
\text { posicionamiento de } \\
\text { las empresas gesto- } \\
\text { ras y el cambio de la } \\
\text { gente en cuanto a la } \\
\text { clasificación de las } \\
\text { fuentes. }\end{array}$ & $\begin{array}{l}\text { siguientes pasos } \\
\text { para la realización } \\
\text { del programa: de- } \\
\text { finición de metas, } \\
\text { convocatoria de la } \\
\text { comunidad, divulga- } \\
\text { ción del proyecto y } \\
\text { de beneficios que ge- } \\
\text { nerará para el grupo } \\
\text { social, y desarrollo } \\
\text { de la obra. }\end{array}$ & $\begin{array}{l}\text { dio de viabilidad, el } \\
\text { planteamiento de } \\
\text { las actividades, la } \\
\text { toma de decisiones, } \\
\text { las instrucciones al } \\
\text { equipo de trabajo, } \\
\text { la presentación de } \\
\text { resultados y la pro- } \\
\text { ducción de material } \\
\text { de divulgación. }\end{array}$ & $\begin{array}{l}\text { bles para su gestión. } \\
\text { Contempló comuni- } \\
\text { caciones por escrito } \\
\text { alárea de prensa, es- } \\
\text { tudio de la situación } \\
\text { de la comunidad, } \\
\text { acompañamiento } \\
\text { del área de prensa } \\
\text { y especificaciones } \\
\text { para la realización de } \\
\text { este trabajo. }\end{array}$ \\
\hline $\begin{array}{l}\text { Proceso } \\
\text { estructu- } \\
\text { rado de } \\
\text { acciones } \\
\text { comunica- } \\
\text { tivas }\end{array}$ & $\begin{array}{l}\text { No hubo proceso } \\
\text { estructurado de ac- } \\
\text { ciones comunicati- } \\
\text { vas, sino actividades } \\
\text { como: estudio de } \\
\text { viabilidad, diagnós- } \\
\text { tico, plan de acción } \\
\text { y cronograma, acer- } \\
\text { camiento a la comu- } \\
\text { nidad, inicio del pro- } \\
\text { yecto y seguimiento. }\end{array}$ & $\begin{array}{l}\text { No existió un proce- } \\
\text { so estructurado de } \\
\text { acciones comunicati- } \\
\text { vas, sino una serie de } \\
\text { acciones que promo- } \\
\text { vieron la cultura del } \\
\text { buen uso del agua, la } \\
\text { sostenibilidad de la } \\
\text { obra y la conforma- } \\
\text { ción de la asociación } \\
\text { de usuarios. }\end{array}$ & $\begin{array}{l}\text { No se dio un proce- } \\
\text { so estructurado de } \\
\text { acciones, sino acti- } \\
\text { vidades como: visitas } \\
\text { a los beneficiados, } \\
\text { prediagnóstico, mo- } \\
\text { tivación de la comu- } \\
\text { nidad, socialización } \\
\text { de la filosofía ReSA, } \\
\text { actividades lúdicas, } \\
\text { talleres y difusión } \\
\text { de información a los } \\
\text { medios. }\end{array}$ & $\begin{array}{l}\text { No hubo un proce- } \\
\text { so estructurado de } \\
\text { acciones comunica- } \\
\text { tivas, sino activida- } \\
\text { des planteadas para } \\
\text { cumplir los objetivos } \\
\text { como: acercamien- } \\
\text { to a la comunidad, } \\
\text { descripción de be- } \\
\text { neficiados, realiza- } \\
\text { ción de objetivos y } \\
\text { metodología, ejecu- } \\
\text { ción, estrategia de } \\
\text { promoción y comer- } \\
\text { cialización y logros e } \\
\text { impactos. }\end{array}$ \\
\hline $\begin{array}{l}\text { Fases o } \\
\text { etapas de } \\
\text { los progra- } \\
\text { mas }\end{array}$ & $\begin{array}{l}\text { Los gestores fueron } \\
\text { los encargados de } \\
\text { planear y ejecutar el } \\
\text { diagnóstico, diseño } \\
\text { estratégico, desa- } \\
\text { rrollo de medios, } \\
\text { implementación y } \\
\text { seguimiento. } \\
\text { La comunidad par } \\
\text { ticipó en la fase de } \\
\text { implementación. }\end{array}$ & $\begin{array}{l}\text { Los gestores fueron } \\
\text { los encargados de } \\
\text { planear y ejecutar el } \\
\text { diseño estratégico, } \\
\text { implementación y } \\
\text { seguimiento. } \\
\text { La comunidad par- } \\
\text { ticipó en la fase de } \\
\text { implementación. }\end{array}$ & $\begin{array}{l}\text { Los gestores fueron } \\
\text { los encargados de } \\
\text { planear y desarrollar } \\
\text { el prediagnóstico, di- } \\
\text { seño de actividades y } \\
\text { medios, implementa- } \\
\text { ción y seguimiento. } \\
\text { La comunidad par- } \\
\text { ticipó en la fase de } \\
\text { implementación. }\end{array}$ & $\begin{array}{l}\text { Los funcionarios de } \\
\text { la Unidad fueron los } \\
\text { encargados de pla- } \\
\text { near y desarrollar el } \\
\text { análisis de la comu- } \\
\text { nidad, diseño de ac- } \\
\text { tividades y medios, } \\
\text { implementación y } \\
\text { seguimiento. } \\
\text { La comunidad par- } \\
\text { ticipó en la fase de } \\
\text { implementación. }\end{array}$ \\
\hline
\end{tabular}


Análisis de la planeación estratégica de la comunicación en cuatro proyectos de intervención social en Montería

\begin{tabular}{|c|c|c|c|c|}
\hline $\begin{array}{c}\text { Sub } \\
\text { categoría }\end{array}$ & $\begin{array}{l}\text { Caso } 1 \\
\text { Reciclando ando }\end{array}$ & $\begin{array}{c}\text { Caso } 2 \\
\text { Plan departamental de } \\
\text { aguas - pda }\end{array}$ & $\begin{array}{c}\text { Caso } 3 \\
\text { Seguridad alimentaria } \\
\text {-resa }\end{array}$ & $\begin{array}{l}\text { Caso } 4 \text { desarrollo } \\
\text { sostenible de las } \\
\text { artesanías }\end{array}$ \\
\hline \multirow[t]{4}{*}{$\begin{array}{l}\text { Caracte- } \\
\text { rísticas de } \\
\text { las fases o } \\
\text { etapas }\end{array}$} & $\begin{array}{l}\text { El diagnóstico fue re- } \\
\text { sultado de observa- } \\
\text { ciones y entrevistas } \\
\text { informales a la co- } \\
\text { munidad. Se recopiló } \\
\text { información relacio- } \\
\text { nada con ubicación } \\
\text { de la población, nú- } \\
\text { mero y característica } \\
\text { de los habitantes, } \\
\text { líderes y formas de } \\
\text { comunicación. }\end{array}$ & $\begin{array}{l}\text { Esta fase fue res- } \\
\text { ponsabilidad de una } \\
\text { firma externa para } \\
\text { identificar el esta } \\
\text { do de Córdoba en } \\
\text { cuanto a los servicios } \\
\text { de agua potable y } \\
\text { saneamiento básico. } \\
\text { Los gestores desco- } \\
\text { nocieron el método } \\
\text { empleado para la re- } \\
\text { colección de la infor- } \\
\text { mación y el análisis. }\end{array}$ & $\begin{array}{l}\text { No existen eviden- } \\
\text { cias del diagnóstico. } \\
\text { En los informes se } \\
\text { abordaron los temas } \\
\text { ubicación geográfica, } \\
\text { caracterización de } \\
\text { los beneficiarios y } \\
\text { descripción del pro- } \\
\text { blema o necesidad, } \\
\text { de manera muy ge } \\
\text { neral sin profundizar } \\
\text { en la situación de la } \\
\text { comunidad. }\end{array}$ & $\begin{array}{l}\text { No existen soportes } \\
\text { digitales o físicos } \\
\text { que evidencien la } \\
\text { fase de diagnóstico. } \\
\text { En el informe final, } \\
\text { se mencionan de } \\
\text { manera muy general } \\
\text { algunos anteceden- } \\
\text { tes y una breve des- } \\
\text { cripción del grupo } \\
\text { social beneficiado. }\end{array}$ \\
\hline & $\begin{array}{l}\text { El diseño estratégico } \\
\text { fue responsabili- } \\
\text { dad de la UPB, que } \\
\text { planteó } 5 \text { estrategias } \\
\text { basadas en los pro - } \\
\text { blemas identificados } \\
\text { por Servigenerales. }\end{array}$ & $\begin{array}{l}\text { Esta fase fue respon- } \\
\text { sabilidad de Acua- } \\
\text { valle, que planteó } \\
\text { las etapas de infor- } \\
\text { mación, divulgación, } \\
\text { articulación con la } \\
\text { sociedad y sosteni- } \\
\text { bilidad social de la } \\
\text { obra. }\end{array}$ & $\begin{array}{l}\text { Esta fase la lideró } \\
\text { la FSI, que planteó } \\
\text { acciones a partir de } \\
\text { los términos de refe- } \\
\text { rencia del contrato, } \\
\text { de las exigencias de } \\
\text { Acción Social y de } \\
\text { su experiencia como } \\
\text { operador. }\end{array}$ & $\begin{array}{l}\text { Esta fase fue respon- } \\
\text { sabilidad de la Uni- } \\
\text { dad, que planteó sie- } \\
\text { te acciones basadas } \\
\text { en los términos de } \\
\text { referencia del con- } \\
\text { venio firmado entre } \\
\text { la CVS y Artesanías } \\
\text { de Colombia. }\end{array}$ \\
\hline & $\begin{array}{l}\text { La UPB diseñó me- } \\
\text { dios de comunica- } \\
\text { ción, que no fueron } \\
\text { socializados con la } \\
\text { comunidad, sino en- } \\
\text { tregados a Servige- } \\
\text { nerales para su pos- } \\
\text { terior divulgación. }\end{array}$ & $\begin{array}{l}\text { Este aspecto no se } \\
\text { contempló como una } \\
\text { fase del programa } \\
\text { de comunicación y/o } \\
\text { componente social. }\end{array}$ & $\begin{array}{l}\text { Este aspecto no se } \\
\text { contempló como una } \\
\text { fase del programa } \\
\text { de comunicación, } \\
\text { sino como una ac- } \\
\text { ción más del diseño } \\
\text { estratégico. }\end{array}$ & $\begin{array}{l}\text { Este aspecto no se } \\
\text { contempló como una } \\
\text { fase sino como una } \\
\text { acción más del dise- } \\
\text { ño estratégico, que } \\
\text { contempló el compo- } \\
\text { nente de divulgación, } \\
\text { liderado por exper- } \\
\text { tos contratados. }\end{array}$ \\
\hline & $\begin{array}{l}\text { La implementación / } \\
\text { Intervención fue lide- } \\
\text { rada por la UPB, y la } \\
\text { comunidad participó } \\
\text { asumiendo roles de } \\
\text { manera voluntaria } \\
\text { en las actividades } \\
\text { desarrolladas. }\end{array}$ & $\begin{array}{l}\text { Esta fase la lideró } \\
\text { Acuavalle. La comu- } \\
\text { nidad participó de } \\
\text { las reuniones, talle- } \\
\text { res, socializaciones y } \\
\text { de forma más activa, } \\
\text { en la conformación } \\
\text { de la asociación de } \\
\text { usuarios. }\end{array}$ & $\begin{array}{l}\text { Esta fase fue llevada } \\
\text { a cabo por el equipo } \\
\text { de trabajo de la FSI. } \\
\text { La comunidad parti- } \\
\text { cipó en las activida- } \\
\text { des que promovían } \\
\text { su vocación agrícola. }\end{array}$ & $\begin{array}{l}\text { Esta fase fue realiza- } \\
\text { da por la CVS, con el } \\
\text { apoyo de funciona- } \\
\text { rios de Artesanías } \\
\text { de Colombia. La co- } \\
\text { munidad participó } \\
\text { en las actividades } \\
\text { que promovían la } \\
\text { comercialización de } \\
\text { la enea. }\end{array}$ \\
\hline
\end{tabular}




\begin{tabular}{|c|c|c|c|c|}
\hline $\begin{array}{c}\text { Sub } \\
\text { categoría }\end{array}$ & $\begin{array}{l}\text { Caso } 1 \\
\text { Reciclando ando }\end{array}$ & $\begin{array}{c}\text { Caso } 2 \\
\text { Plan departamental de } \\
\text { aguas }-p d a\end{array}$ & $\begin{array}{c}\text { Caso } 3 \\
\text { Seguridad alimentaria } \\
\text {-resa }\end{array}$ & $\begin{array}{c}\text { Caso } 4 \text { desarrollo } \\
\text { sostenible de las } \\
\text { artesanías }\end{array}$ \\
\hline & $\begin{array}{l}\text { No hubo evaluación } \\
\text { del programa de co } \\
\text { municación, sino una } \\
\text { retroalimentación } \\
\text { una vez finalizada } \\
\text { cada actividad. }\end{array}$ & $\begin{array}{l}\text { No hubo evaluación } \\
\text { del programa, sino } \\
\text { seguimiento, aunque } \\
\text { este se realizó a la } \\
\text { obra y no a las accio- } \\
\text { nes del componente } \\
\text { social. }\end{array}$ & $\begin{array}{l}\text { No hubo evaluación } \\
\text { del programa, sino } \\
\text { seguimiento por par- } \\
\text { te de los gestores del } \\
\text { proyecto y de fun- } \\
\text { cionarios de Acción } \\
\text { Social. }\end{array}$ & $\begin{array}{l}\text { No hubo evaluación } \\
\text { del programa. Las } \\
\text { actividades contem- } \\
\text { plaron un espacio } \\
\text { de retroalimentación } \\
\text { que sirvió para hacer } \\
\text { seguimiento al pro- } \\
\text { yecto. }\end{array}$ \\
\hline
\end{tabular}

Fuente: Ana Lorena Malluk Marenco

\section{Conclusiones}

- Las organizaciones dedicadas a la gestión de proyectos de intervención social usaron la comunicación como medio, y limitaron la inversión de recursos humanos, físicos y materiales para este fin, debido al tiempo reducido de los proyectos, a los fines inmediatistas de las agencias financiadoras y organizaciones gestoras, a la visión limitada de los gestores del desarrollo en cuanto a la planeación, gestión e impacto de la comunicación y a la falta de vinculación de profesionales de la comunicación expertos en el proceso de planeación de la comunicación.

- Según los gestores de los proyectos, la comunicación fue decisiva para alcanzar las metas propuestas, obtener resultados positivos, facilitar el proceso de información y divulgación, acceder a los medios, ganar visibilidad, hacer propaganda, facilitar la gestión institucional o desarrollar la estrategia publicitaria. Los programas de comunicación objeto de estudio son de enfoque instrumental, difusionista y autoritario porque fomentaron la verticalidad y unidireccionalidad en la relación organizaciones/ emisores - comunidades/receptores.

- Las intervenciones fueron dirigidas debido a que en los cuatro casos las organizaciones respondieron a las políticas nacionales en materia de desarrollo social; a los intereses ideológicos, filosóficos y políticos de quienes los dirigen, apoyan o financian; a su experiencia, tiempo, capacitación y recurso humano para la puesta en marcha de este tipo de iniciativas; y a su necesidad de incidir en los espacios y colectivos que tienen problemas, con el fin de equilibrar los imperfectos o desequilibrios ocasionados, sin transformar la sociedad en su conjunto.

- Las comunidades beneficiadas reconocieron algunos de los resultados propuestos en los proyectos, en especial, aquellos en los que colectivamente se generó el bienestar de la población. Aunque existe recordación, agradecimiento y confianza hacia la labor realizada por las organizaciones, los resultados obtenidos no siempre dieron respuesta a las necesidades, prioridades y expectativas de estos grupos. En los cuatro casos, los resultados e impacto identificados por la comunidad estuvieron relacionados con el proyecto y no con el programa de comunicación estratégica. 
- No se pudo determinar, según los resultados y el impacto obtenido, el modelo de planeación del programa de comunicación estratégica más efectivo empleado por las organizaciones, debido a que estas no gestionaron la comunicación de forma organizada, planeada, sistemática, integradora, sinérgica, coherente, probada y articulada al proceso de planeación de los proyectos de intervención social.

- A pesar de que las organizaciones no emplearon un modelo para la planeación de los programas, desarrollaron las fases de diagnóstico, diseño estratégico, implementación y seguimiento. En tres de los casos objeto de estudio, los encargados de esta labor, que por lo general fueron ingenieros, administradores, economistas o técnicos, desconocieron la metodología para la gestión de este tipo de programas. Por su parte, las agencias financiadoras no le sugieren o exigen a estas organizaciones el uso de un marco de referencia que les permita articular la comunicación al proceso de planeación de los proyectos de intervención social.

- Las fases que predominaron fueron el diagnóstico, en el que se realizó un análisis técnico y superficial de la situación; el diseño estratégico, que también incluyó la producción de medios, y la implementación, en la que se realizó el seguimiento de las actividades. Estas acciones fueron responsabilidad de los gestores de los proyectos y el papel de la comunidad se redujo a ser fuente de información para la recopilación de los datos y a acatar las decisiones tomadas con anterioridad por los gestores.

- Las organizaciones llevaron a cabo acciones de comunicación que aportaron al logro de los objetivos de los proyectos; en ninguno de los casos, se realizaron estas actividades en el marco de un programa de comunicación estratégica. Estas acciones no combinaron, de manera sistemática y planeada, métodos, técnicas y herramientas de comunicación con el fin de promover un cambio concreto y garantizar el cumplimiento de los objetivos.

\section{Bibliografía}

Beltrán, Luís (1995). Comunicación para el desarrollo: una evaluación al cabo de cuatro décadas. Lima: Mineo.

Gumucio, Alfonso (2001). Haciendo olas: historias de comunicación participativa para el cambio social. La Paz Bolivia: Plural Editores.

McMillan, James y Schumacher, Sally (2005). Investigación educativa. Madrid. Editorial Pearson Educación, S. A. 
